\title{
Pioneros e ignorados: La escuela de París y la doctrina europea de las relaciones públicas
}

\author{
Jordi Xifra \\ Profesor de Teoría y Técnicas de las Relaciones Públicas \\ Escuela Universitaria de Ciencias de la Comunicación \\ Universidad de Gerona
}

\begin{abstract}
Resumen
En los últimos treinta años, la teoría de las relaciones públicas ha observado un amplio desarrollo a través de la comunidad científica estadounidense. Sin embargo, en la década de 1970, Europa asistió a la creación y rápida extinción de una escuela de pensamiento, la escuela de París, que desarrolló lo que hoy se conoce en círculos muy específicos como la doctrina europea de las relaciones públicas. A pesar de que los autores europeos fueron pioneros en destacar la dimensión empresarial y relacional del fenómeno de las relaciones públicas, su acogida en Estados Unidos fue nula y su reconocimiento ignorado. El propósito de este artículo es presentar el ideario básico de esta doctrina de las relaciones públicas, cuyos principios están plenamente vigentes y conforman las actuales problemáticas de investigación de la disciplina. Aún así, la escuela de París permanece como una gran desconocida en la actual comunidad científica conformada mayoritariamente por investigadores norteamericanos.
\end{abstract}

\begin{abstract}
In last thirty years, public relations theory has been developed through the contributions of the American scientific community. However, in the decade of seventies, a new school of thought was created in Europe and quickly extinct, the School of Paris, which developed the today known as the European doctrine of public relations. In spite of European authors were pioneers in emphasize the organizational and relational dimension of the public relations phenomenon, the reception of their ideas in the United States was void and its recognition ignored. The purpose of this article is to show the basic ideas of that public relations doctrine, which principles are entirely applicable and constitute the present research problems in the field. Nevertheless, the school of Paris remains unknown in the present scientific community formed basically by American researchers.
\end{abstract}

Palabras clave: Relaciones públicas/Doctrina europea de las relaciones públicas/Teoría de las relaciones públicas/Escuela de pensamiento.

Key words: Public relations/European doctrine of public relations/Public relations theory/School of thought 


\section{INTRODUCCIÓN: LA METÁFORA DE LA “ESCUELA DE PENSAMIENTO” EN EL ÁMBITO DE LA COMUNICACIÓN}

diferencia de la teoría norteamericana ${ }^{1}$, la doctrina europea de las relaciones
públicas está formada por un cuerpo intelectual extremadamente uniforme y
homogéneo que la convierte en la primera escuela doctrinal de la historia de la disciplina. En efecto, una escuela teórica o doctrinal es el conjunto de investigadores, pensadores, teóricos que se sienten concernidos por una disciplina y que comparten unas definiciones comunes del fenómeno, de los problemas a resolver y de las técnicas, métodos y estrategias apropiadas para resolverlos, y un lugar institucional común.

Attallah (1991), refiriéndose a las escuelas de comunicación, explica que la condición necesaria para poder hablar de "escuela" es poseer una definición común del objeto de estudio. Otra cosa serán las diferencias ontológicas entre escuelas producidas por el contexto de la investigación ${ }^{2}$ o por la naturaleza de los teóricos ${ }^{3}$.

Los problemas de investigación consisten en los intereses comunes de investigación formulados en términos comparables por los miembros de una escuela. De una misma definición pueden inferirse problemáticas distintas. En la comunicación de masas, todas las escuelas citarán el elemento medio de comunicación social en su definición. Sin embargo, las problemáticas que se derivan son diferentes según las escuelas.

Por otro lado, los miembros de una misma escuela teórica han de tener una concepción idéntica de los medios; es decir, de las técnicas, los métodos y las estrategias pertinentes (adaptadas al objeto de estudio) que han de adoptarse para resolver los problemas previamente definidos. Por lo tanto, poco importa que las estrategias confirmen la definición; han de ser pertinentes.

El lugar de la escuela puede ser real o imaginario. Por ejemplo, los miembros de la escuela de Frankfurt investigaban desde Nueva York, Los Ángeles, París o Frankfurt. La escuela de Palo Alto, sin ir más lejos, está muy ligada a su sede institucional de investigación, el Mental Research Institute de Palo Alto (California), pero, en cambio, se formó a partir de un proyecto intelectual compartido, ya que sus fundadores, los psiquiatras Paul Watzlawick y Don D. Jackson, antes de crearlo, sólo se conocían por su interés común en la cibernética.

\footnotetext{
${ }^{1}$ Sobre el desarrollo de la teoría de las relaciones públicas en Estados Unidos, véase Botan y Taylor (2004).

${ }^{2}$ La cibernética, por ejemplo, nació en el seno del contexto industrial militar de los Estados Unidos, constituyendo un modelo para resolver la complejidad de las estructuras económicas y sociales.

${ }^{3}$ La comunicación se ha estudiado primero desde la perspectiva cibernética para introducirse después en el terreno sociológico, psicológico, político o empresarial.
} 


\section{LA ESCUELA DE PARÍS: ORÍGENES Y PRINCIPIOS}

En el territorio intelectual de las relaciones públicas, la escuela de París, primera de las dos escuelas de las relaciones públicas existentes hasta la fecha - la segunda es la escuela de Maryland, surgida de la obra investigadora de James Grunig y constituida por él, algunos de sus colegas y sus discípulos-, se concentra en los principios de su fundador, Lucien Matrat, que han sido asumidos por sus adeptos casi al pie de la letra. Unos principios que beben en las ideas de autores norteamericanos como Bernays, Cutlip, Center, Canfield, Moore y Lesly ${ }^{4}$, aunque ninguno de ellos reconoce explícitamente dicha paternidad intelectual.

De la escuela de París emerge la doctrina europea de las relaciones públicas, que constituye una teoría normativa que no se basa en ninguna investigación de carácter empírico. La doctrina europea se caracteriza por dos aspectos fundamentales; uno de naturaleza temporal y otro de naturaleza espacial. El temporal alude a que se trata de una doctrina muy concentrada en el tiempo (la primera mitad de la década de 1970), que emerge y se fundamenta en un texto concreto (casi un credo): la conferencia que pronunció el por entonces presidente y fundador del Centre Européen des Relations Publiques (CERP) ${ }^{5}$ - hoy Confédération Européenne des Relations Publiques-, Lucien Matrat, en el Institut de Sociologie de la Universidad de Bruselas el 8 de abril de 1970, y que luego fue desarrollada por otros miembros de la CERP dedicados a la enseñanza, en concreto Ugeux (1973), Huisman et al. (1981), Lougovoy (1981) y Boiry (1989, 2004).

La característica espacial, derivada de la anterior, es su ubicación en el ámbito de los países francófonos y particularmente en Francia, con una pobre expansión fuera de este país si no es en los trabajos de personalidades vinculadas a la CERP, como August Ferrer, presidente de honor de esta asociación y uno de los profesionales más destacados del panorama español de las relaciones públicas, o el belga Jean-Marie Van Bol, también miembro activo y antiguo presidente.

\footnotetext{
${ }^{4}$ Al contrario, los autores norteamericanos - salvo alguna excepción, como Newsom et al. (2000) - en las investigaciones y trabajos coetáneos y posteriores a los textos de miembros de la escuela de París como Matrat, Ugeux o Van Bol, no citan estas obras. Esta omisión es sorprendente desde el punto de vista corporativo, dado que la International Public Relations Asociation (IPRA), de la que formaban parte los principales eruditos norteamericanos, adoptó el mismo código ético que el Centre Européen des Relations Publiques (CERP), cuyo autor fue Matrat - luego presidente de honor de la IPRA-, en el congreso anual celebrado conjuntamente por ambas asociaciones en Atenas, en 1965.

${ }^{5}$ Sobre los orígenes de la CERP y del asociacionismo en general, véase la edición castellana de Lougovoy y Linon (1969). La primera edición original de esta obra, si bien es anterior a la fecha del texto fundacional de Matrat, recoge su espíritu y en ella se nota la huella de sus ideas, esbozadas por vez primera en público en una conferencia ofrecida en el $\mathrm{I}^{\mathrm{er}}$ Colloque sur les Relations Publiques organizado por la Cámara de Comercio e Industria de París en 1962, y luego plasmadas en el Código de Atenas de 1965.
} 
La raíz de la doctrina europea de las relaciones públicas ${ }^{6}$ se encuentra en la implantación de la profesión en Francia. Las relaciones públicas se instauran en Europa con la llegada de las tropas norteamericanas durante la Segunda Guerra Mundial, que contaban con oficiales encargados de las relaciones con la prensa y con otros responsables de las relaciones con la población civil llamados "oficiales de relaciones públicas" ${ }^{\prime 7}$. No obstante, la aplicación del plan Marshall dinamizó realmente el desarrollo de la actividad, ya que un grupo de empresarios franceses se desplazó a los Estados Unidos en las denominadas "misiones de productividad" y descubrieron las relaciones públicas como profesión. De esta manera, Jean Choppin de Janvry, de vuelta de una de estas misiones, creó en 1946 el primer departamento de relaciones públicas de la compañía Esso Standard. Iniciativa que fue seguida por otras empresas petroleras, como Shell y Caltex ${ }^{8}$. Ese mismo año se crean las primeras agencias en Holanda.

Entre los responsables de relaciones públicas de las petroleras se encontraba Matrat, en la empresa Caltex ${ }^{9}$. El 8 de mayo de 1959, en Orleáns, el padre de la doctrina europea fundó con otros colegas la CERP, que en 1965 aprobó el código de ética internacional de las relaciones públicas, conocido como Código de Atenas por haberse adoptado en el encuentro anual celebrado en la capital griega ${ }^{10}$. Matrat fue el autor del texto y en él se concreta en el espíritu último de la teoría europea: la dimensión ética de las relaciones públicas.

Tres son los criterios principales sobre los que descansa la doctrina europea: los fundamentos antropológicos de las relaciones públicas, la dimensión empresarial de las relaciones públicas y el concepto de confianza como elemento central del modelo de las relaciones públicas.

"La expresión "doctrina europea de las relaciones públicas" la utiliza por vez primera Matrat en 1970.

7 Antes de la guerra, sin embargo, existían ciertas iniciativas aisladas, como la de la empresa Renault, que desde 1937 contaba entre su personal con un "ingeniero social" encargado de las relaciones con los trabajadores. Otras organizaciones, como Péchyney, publicaban informaciones financieras muy detalladas dirigidas a los accionistas o al público en general (Huisman, 1981).

${ }^{8}$ En los Estados Unidos, a principios del siglo XX, las petroleras también fueron pioneras en utilizar las relaciones públicas, debido a la ola de nacionalizaciones posterior a la Primera Guerra Mundial (ferrocarriles, electricidad, gas, etc.) que hizo que las compañías productoras de petróleo se sintiesen amenazadas. Ante esa situación, se esforzaron por darse a conocer al público y explicar su política y objetivos.

${ }^{9}$ Posteriormente, en la década de 1970, Matrat fue director de relaciones públicas de Elf.

${ }^{10}$ Como ha sido apuntado, el Código de Atenas fue revisado en el congreso anual de Teherán, el 17 de abril de 1968, celebrado simultáneamente por la IPRA y el CERP. 


\section{LOS FUNDAMENTOS ANTROPOLÓGICOS DE LAS RELACIONES PÚBLICAS}

Para la escuela de París, la empresa vive y se desarrolla en el interior de un "plasma" constituido por el conjunto de los públicos de los que recibe las aportaciones necesarias para su subsistencia: aportación de ideas, aportación de trabajo, aportación de capital y aportación de autorizaciones. Apunta Ferrer (1993) que aunque la empresa no puede vivir sin estas aportaciones, los grupos de individuos que aportan ideas, trabajo, capital y autorizaciones no son la empresa. Ellos pueden cambiar mientras que la organización sigue. Pero es evidente que ésta depende de sus públicos, internos y externos.

Existe, por consiguiente, una dependencia sistémica de la empresa respecto de sus públicos para conseguir la realización de sus objetivos. Esta dependencia exige comunicación y, por ende, una política de relaciones públicas adecuada al esquema citado. Sin embargo, ambos actores están formados por individuos (hombres y mujeres), por seres humanos, por lo que el objetivo final de la empresa ha de ser el hombre. En la sociedad actual nos encontramos con tres tipos de hombre: el productor, el consumidor y el social. El hombre productor se caracteriza por ofrecer una cantidad y calidad de trabajo, cuyo objetivo es llevar al individuo a producir más, más rápido y mejor. El hombre consumidor es aquel que realiza una cantidad y calidad de compras y consumos, con el objetivo de adaptar la máxima cantidad de productos a sus necesidades.

Las relaciones públicas se interesan por tercer tipo: el hombre social. Constituye su razón de ser, su fundamento antropológico y social. El hombre social se caracteriza por crear y adecuar sus opiniones, sus juicios y sus relaciones, tendiendo a crear un clima y conseguir un comportamiento favorable al desarrollo de las organizaciones en la sociedad, en su entorno (Matrat, 1975; Ferrer, 1993, Boiry, 2004). También se caracteriza por la naturaleza de sus relaciones (es padre, hijo, alumno, profesor, elector, diputado, obrero, jefe, etc.), que lo definen respecto del resto del grupo o de la sociedad, y por la calidad de sus relaciones (puede orientar o boicotear, crear confianza o desconfianza, ser afectivo o negativo, etc.), que lo hacen incidir en el comportamiento individual y/o colectivo. El hombre ha de satisfacer ciertas necesidades elementales para sobrevivir y, desde que existen las sociedades, conoce también necesidades biológicas tan importantes y no menos urgentes y exigentes que las necesidades elementales. Es en este punto donde la doctrina europea distingue entre las necesidades del tipo deber (debe alimentarse, debe vestirse, debe habitar, etc.) y las del tipo ser (ser informado, ser considerado, ser respetado, ser comparado, etc.).

A partir de lo expuesto, esta visión antropológica y humanística reconoce, ateniéndose a las necesidades, tres personajes en el hombre social: la persona, el colaborador y el fabricante de opinión. Cada uno con una necesidad propia: la persona se distingue por su deseo de dignidad, el colaborador por su deseo de participación responsable y solidaria, y el fabricante de opinión se identifica por la necesidad de información y su deseo de comunicación asimilable, rigurosa y comprensible. 
La importancia de la doctrina europea radica precisamente en la consideración de la persona desde la óptica de las relaciones públicas, en el sentido de que satisfacer la dignidad de la persona no es la tarea propia de una técnica concreta, sino de una moral elemental. Tratar al otro como persona es tratarlo como nuestro igual al nivel de la dignidad y prohibirnos, respecto de terceros, todo acto o palabra que juzgaríamos susceptible de atentar a nuestra propia dignidad. En este punto se encuentra el principal pilar de la teoría europea de las relaciones públicas traducida en el Código de Atenas. Los considerandos que sirven de preámbulo a este código deontológico — cuya autoría es de Matrat- así lo prueban, amén de compendiar buena parte del ideario de la escuela de París:

«CONSIDERANDO que todos los países miembros de la Organización de las Naciones Unidas han aceptado respetar su Carta proclamando "su fe en los derechos fundamentales del hombre, en la dignidad y el valor de la persona humana..." y que, por este motivo, así como por la naturaleza misma de su profesión, los practicantes de las relaciones públicas de estos países han de comprometerse a conocer y respetar los principios contenidos en esa Carta;

CONSIDERANDO que el hombre, además de sus "derechos", tiene unas necesidades que no son solamente de orden físico o material, sino también de orden intelectual, moral y social, y que el hombre puede realmente gozar de sus derechos en la medida en que estas necesidades —en aquello que tienen de esencial- son satisfechas;

CONSIDERANDO que los profesionales de las relaciones públicas pueden, en el ejercicio de su profesión, según la manera de ejercerlas, contribuir ampliamente a satisfacer estas necesidades intelectuales, morales y sociales del hombre;

CONSIDERANDO, finalmente, que la utilización de las técnicas que permiten entrar en contacto simultáneamente con millones de individuos, otorga a los profesionales de las relaciones públicas un poder que ha de limitarse para el respeto de una estricta moral;

Por todas estas razones, las asociaciones de relaciones públicas abajo firmantes DECLARAN: que adoptan como carta moral los principios del Código de Ética expuestos a continuación y que toda violación de este Código por alguno de sus miembros en el ejercicio de su profesión y cuando sea probada ante la Junta, será considerada como falta grave, y comportará una sanción inmediata»"

En lo que atañe al hombre social considerado como colaborador, Matrat (1971, 1975) considera que las relaciones públicas empresariales han de contribuir a reunir las condiciones que hacen que cada colaborador se sienta: 1) concernido por el "juego" de la empresa, porque sabe ubicar su participación en este juego; 2) responsable de las "cartas" que juega, pues tiene la iniciativa que obliga a sospesar las ventajas y los inconvenientes de sus decisiones; 3 ) solidario con los otros

${ }^{11}$ La influencia del Código de Atenas e, indirectamente, de las aportaciones de Matrat no se centró en Europa occidental. Los códigos de ética han sido el único instrumento regulador del ejercicio de las relaciones públicas del que se han dotado las principales asociaciones profesionales, tanto nacionales como internacionales. 
colaboradores, ya que tiene el sentimiento de formar parte de un equipo y percibe los vínculos de interdependencia que existen entre él y ese equipo, y 4) considerado por los otros colaboradores, porque sabe que sus esfuerzos son apreciados y siente a su alrededor la confianza necesaria para ser plenamente él mismo.

El papel de la comunicación y de la información en la satisfacción de estos cuatro objetivos será fundamental, y constituirá el segundo elemento relevante de la doctrina europea: la consideración plena de las relaciones públicas como una ciencia de la comunicación, ya que, parafraseando a Matrat (1971), disciplina social fundada sobre el respeto de una ética rigurosa, las relaciones públicas son también una ciencia de la comunicación que permite abordar los problemas de la empresa bajo la luz de un nuevo día más conforme a sus realidades socio-económicas.

Finalmente, el hombre social no intercambia sólo trabajo con dinero, como sucede con el hombre productor, o dinero con productos, como lo hace el hombre consumidor. El hombre social intercambia opiniones, juicios e ideas. Únicamente ejercerá con un mínimo de objetividad la función de "fabricante de opinión" si recibe las informaciones que le permitan conocer, comprender, juzgar, expresarse y comunicar (Matrat, 1975).

Este aserto incide en un punto clave y muy poco estudiado: el del diálogo social como fundamento sociológico de las relaciones públicas. La evolución histórica de las relaciones públicas se realizó en una serie de fases que se vinculaban con el reconocimiento de un conjunto de derechos fundamentales de la sociedad, el primero de los cuales es el derecho a la información, la sociedad —el "público"tiene el derecho de estar informada de cuantas actividades la afecten o pueden afectarla (Solano, 1995; Xifra, 2005).

Enlazamos así con otra de las cuestiones relevantes a la hora de estudiar las relaciones públicas, la de la responsabilidad social, pues, como declara Ugeux, «una preocupación de relaciones públicas es una preocupación constante, una especie de respuesta de los responsables sociales a las necesidades de participación de su entorno porque, en su primer estadio, esta necesidad se expresa interrogativamente, en forma de curiosidad social, y desemboca en juicios que, aunque son sucintos, no excluyen la gravedad» (1973, pág. 28).

\section{LA DIMENSIÓN EMPRESARIAL}

A pesar de su fundamento antropológico y humanístico, la doctrina europea, a imagen y semejanza de las teorías de las relaciones públicas, no se escapa a la hora de otorgarles una función empresarial primordial. La obra capital de Matrat, en la que se basa toda la doctrina, se titula Relations publiques et management $(1971)^{12}$ y en ella deja muy claro que las relaciones públicas forman parte de las

\footnotetext{
${ }^{12}$ Que es la trascripción de la conferencia, a la que nos hemos referido, pronunciada el año anterior.
} 
estrategias utilizadas por el management para responder a las expectativas y actuar sobre las motivaciones de los públicos, cuyos comportamientos, juicios y opiniones pueden influenciar la marcha o el desarrollo de la empresa.

Los miembros de la escuela de París no contemplan la aplicación de las relaciones públicas a cualquier tipo de gestión de las organizaciones. Al contrario, consideran que su adecuación sólo es posible en la dirección participativa por objetivos, el sistema de dirección más completo. Nutrido de aportaciones de la psicología social, este sistema directivo espera del personal de la organización que fije él mismo los objetivos a conseguir, para aumentar sus motivaciones y de esta manera responder mejor a las necesidades de la empresa. La dirección participativa por objetivos confiere a cada uno una gran autonomía en la elaboración de los objetivos, otorgando al proyecto de empresa un papel esencial de la gestión y elevándolo a técnica esencial de las relaciones públicas (Boiry, 1989; Ferrer, 1993; Xifra, 2006).

Llegados a este punto, es innegable que la doctrina europea supone, pues, un eslabón metodológico entre la concepción norteamericana de las relaciones públicas de mediados del siglo XX y el filón investigador que se desarrollará en los Estados Unidos a partir, sobre todo, de la década de 1980. Sin embargo, la actual comunidad científica de la disciplina, plenamente dominada por académicos norteamericanos, ignora este factor. Así, cuando analizan el concepto de relaciones públicas, se afirma que, a partir de la década citada, los teóricos más avanzados de las relaciones públicas solucionan la cuestión de la unificación de criterios a la hora de identificar la naturaleza de la disciplina como una filosofía, política o función gerencial, aspecto éste que, según Hutton (1999), se había diluido en la década anterior. Esta aseveración margina las ideas de los autores europeos que, precisamente en la década anterior a la de 1980, conceptualizaron las relaciones públicas como una política de dirección de la empresa o función directiva (Lougovoy y Linon, 1969; Matrat, 1971; Ugeux, 1973; Boiry, 1989; Ferrer, 1993). En este sentido, la doctrina europea sigue siendo hoy la aportación teórica más olvidada no sólo en el campo de las relaciones públicas, sine en el de las disciplinas de la comunicación en general.

\section{LA CONFIANZA COMO ELEMENTO INTEGRADOR DE LA DOCTRINA EUROPEA: LA DIMENSIÓN RELACIONAL}

Los investigadores de las relaciones públicas han utilizado ciertos axiomas para definirlas. El más conocido ha sido el de "hacerlo bien y hacerlo saber" (Revilla, 1970). Para Matrat (1971), adoptar una política de relaciones públicas es, en primer lugar, aceptar conciliar el interés de la empresa y el interés de quienes depende su progresión. Practicar una política de relaciones públicas es, posteriormente y sólo posteriormente-, iniciar una política de comunicación capaz de establecer y mantener relaciones de confianza con el conjunto de públicos de la empresa. Esta es, según el autor, la clave que separa las relaciones públicas de las otras 
formas de la comunicación persuasiva, como la publicidad y la propaganda. Desde el momento en que la publicidad es la estrategia del deseo que motiva la demanda de un producto o servicio, y la propaganda la estrategia del condicionamiento que sustituye las acciones reflexivas por actos reflejos, las relaciones públicas son la estrategia de la confianza que otorga a la comunicación su autenticidad (Matrat, 1971; Boiry, 1989; Ferrer, 1993).

El concepto de confianza incide en la dimensión psicológica y social de las relaciones públicas. Para el hombre, observa Matrat (1971), sus relaciones son las raíces mediante las que se integra al grupo. Si son buenas, es decir, de confianza, se integra bien y obtiene la afectividad necesaria para la satisfacción relacional. Para la empresa, la calidad de las relaciones que se establecen determina su cohesión y, por consiguiente, su efectividad. Por otra parte, de la calidad de las relaciones entre la empresa y su ecosistema dependerá su correcto desarrollo. La organización no puede vivir ni prosperar sin la confianza de su entorno, de su público. De ahí que las relaciones públicas no puedan considerarse un conjunto más o menos homogéneo de técnicas comunicativas insuficientes para alcanzar la adhesión y la participación de los públicos. Su objetivo esencial las condena a ser en primer lugar una disciplina social, una manera de ser, de comportarse, de actuar, una regla del juego social que preserva la integridad y la dignidad de cada uno.

Ese objetivo esencial, el elemento teleológico de las relaciones públicas, es, para la escuela de París, la contribución a crear un clima de confianza y la realización de las condiciones de la participación efectiva y afectiva derivada de la consideración de colaborador del hombre social. Otra cosa es que la consecuencia de esta situación sea la formación de una imagen institucional honesta, más que la finalidad propia de las relaciones públicas, como defienden Matrat y sus discípulos.

En este punto queremos poner de relieve el hecho de que los autores europeos que nos ocupan pueden considerarse, a pesar de la escasa profundización analítica de que hicieron gala, pioneros en abordar las relaciones públicas desde la perspectiva relacional (que en Estados Unidos inició Ferguson en 1984... ¡sin referencia alguna a los trabajos de los autores objeto de nuestro estudio!), con una intencionalidad alejada de los criterios propios de la metodología del estudio de la comunicación de masas y centrada en la creación y mantenimiento de relaciones entre estructuras sociales. Lo demuestra la que podríamos describir como definición oficial de la doctrina europea, considerada por algunos como una de las más acertadas por su minuciosidad y su carácter integrador de la pluralidad de elementos que la estructuran: «Las relaciones públicas son, al nivel de pensamiento y acción, una política directiva de la empresa o de cualquier estructura social que tiene como objetivo, vinculado a una vigilancia constante sobre las diferentes opiniones de los estamentos circundantes, crear un clima de afecto y de confianza entre todos ellos mediante la difusión directa, o a través de los medios de comunicación, de informaciones honestas y completas sobre el parentesco entre 
las finalidades y los procedimientos de aquéllas y el bien común» (Ugeux, 1973, págs. 32-33). En estas líneas quedan claramente expresados los signos de identidad de la comunidad intelectual que nos ocupa. Con ánimo de esclarecer su alcance integrador y estructural-comunicativo, es oportuno detenernos brevemente en sus elementos:

- Una persona (física o jurídica) nombrada emisor de las relaciones públicas que actúa de forma directa o a través del canal de una organización de especialistas a quienes confía su problema de relaciones públicas.

- La aceptación, por ese emisor, de la necesidad permanente o sistemática de una nueva dimensión en sus responsabilidades de gestión que nunca le permitirán desinteresarse de la opinión de su entorno humano respecto de su cuestión o problema.

- Unos públicos diversos, llamados receptores de las relaciones públicas, destacando que aunque no tengan opiniones concordantes con las del emisor, son todos -y siempre- importantes para su supervivencia o prosperidad atendiendo a las decisiones que pueden tomar.

- Una concepción del bien general que sea común a los diferentes públicos y al emisor. La confianza únicamente puede nacer por referencia a unos valores superiores al interés inmediato de emisor y receptor. El concepto de bien común no está lejos del concepto actual de responsabilidad social.

- Una tipología de relaciones entre el emisor y sus públicos que, de una parte, facilite las actividades profesionales del emisor y quizá del receptor y, de otra, sitúe sus relaciones económicas, sociales y políticas en un plano de comprensión, de estima y, en el mejor de los casos, de simpatía recíproca. El concepto de simpatía debe considerarse sinónimo de entendimiento mutuo.

- La observación y seguimiento de los fenómenos de opinión indispensable para la definición de la política de gestión y de relaciones.

- La referencia a la utilización, como herramienta, de las técnicas de la comunicación social en el sentido amplio del término.

Podemos reparar que se trata de una perspectiva estructurada y estructural de las relaciones públicas, que compendia el espíritu de una doctrina cuyo punto de partida, no conviene olvidarlo, se encuentra en los estudios norteamericanos de la época y, muy especialmente, en la obra de pionera de Cutlip y Center (1952).

La escuela de París se fue extinguiendo a medida que sus miembros, ajenos al campo académico, dejaron de escribir sus reflexiones, y hoy sólo se actualiza 
al compás de las sucesivas ediciones del libro de Chaumely y Huisman (1997), monografía sobre la disciplina de la prestigiosa colección francesa Que sais-je? Los temores de Matrat (1987) cuando alertó que los profesionales de las relaciones públicas - los franceses, se entiende - las reducen a una mera técnica de comunicación o las diluyen en una "comunicación global" constituida por "trozos esparcidos" de disciplinas con objetivos distintos (lo que comporta la "confusión total" de tales objetivos), parecen confirmarse. Un síntoma incontestable: la literatura francesa sobre las relaciones públicas, amén de la reedición citada, es casi nula. Otra cosa es la producción literaria francófona llegada de Canadá —tampoco copiosa, pero más regular- cuyos autores están ligados a la doctrina europea por ser antes destacados profesionales que ilustres académicos, aunque están más influenciados por una visión norteamericana de las relaciones públicas (Dagenais, 1999; Maisonneuve et al., 2000).

Las escuelas de pensamiento consolidadas no se identifican con las aportaciones de un único intelectual. Las relaciones públicas, como cualquier otra disciplina científica, no deben ser el magisterio de una sola persona. La doctrina europea, a pesar de la enorme influencia de Matrat, no es la doctrina Matrat. Ugeux, en Francia, Van Bol, en Bélgica, y Ferrer, en España, lo han demostrado. En Estados Unidos, a partir de la década de 1980, sobresalieron por encima de todas y sin parangón anterior las aportaciones de James Grunig. Si Edward L. Bernays es considerado el padre de las relaciones públicas como arte, Grunig lo es de las relaciones públicas modernas en tanto que disciplina científica. Pero el terreno estaba abonado por un grupo de profesionales y académicos europeos que cimentaron los fundamentos de un cuerpo doctrinal aún vigente y con una importante perspectiva de desarrollo.

\section{BIBLIOGRAFÍA:}

ATTALLAH, P. (1991). Théories de la communication: Sens, sujets, savoirs, Sillery, Presses de l'Université du Québec.

BOIRY, P.A. (1989). Les relations publiques ou la stratégie de la confiance, París, Eyrolles (trad. cast.: Relaciones públicas o la estrategia de la confianza. Barcelona, Gestión 2000, 1998).

BOIRY, P.A. (2004). Des publics-relations aux relations publiques: la doctrine européenne de Lucien Matrat. París: L'Harmattan.

BOTAN, G. M. y TAYLOR, M. (2004). Public Relations: State of the Field. Journal of Communication, December 2004, 645-661.

CHAUMELY, J. y HUISMAN, D. (1997). Les relations publiques, París, Presses Universitaires de France, $7^{\text {a }}$ edición.

CUTLIP, S.M. y CENTER, A.H. (1952). Effective public relations, Englewood Cliffs, Prentice-Hall (trad. cast.: Relaciones públicas, Madrid, Rialp, 1963). 
DAGENAIS, B. (1999). Le métier de relationniste, Sainte-Foy, Les Presses de l'Université de Laval.

FERGUSON, M. A. (1984, agosto). Building theory in public relations: Interorganizational relationships as public relations paradigm. Comunicación presentada en la conferencia annual de la Association for Education in Journalism and Mass Communication. Gainesville, FL.

FERRER, A. (1993). Relaciones públicas, empresa y sociedad, Girona, Escola Superior de Relacions Públiques de Girona, $2^{\underline{a}}$ edición.

HUISMAN, D. (1981). "Historique: Quelques étapes du développement des relations publiques", en C. LOUGOVOY y D. HUISMAN, Traité de relations publiques, París, Presses Universitaires de France.

HUISMAN, D., UGEUX, W. y BARRÈRE, J.J. (1981). "Vers une définition des relations publiques", en C. LOUGOVOY y D. HUISMAN, Traité de relations publiques, París, Presses Universitaires de France.

HUTTON, J.G. (1999). "The definition, dimensions, and domain of public relations", Public Relations Review, 25(2), 199-214.

LOUGOVOY, C. (1981). "L'entreprise moderne et son environement", en C. LOUGOVOY y D. HUISMAN, Traité de relations publiques, París, Presses Universitaires de France.

LOUGOVOY, C. y LINON, M. (1969). Les relations publiques: Fonction de gouvernement de l'entreprise et de l'administration, París, Dunod (trad. cast.: Relaciones públicas: Función de gobierno de la empresa y de la administración, Barcelona, Hispano Europea, 1978, 3aㅡ edición).

MAISONNEUVE, D., LAMARCHE, J.F. y ST-AMAND, Y. (2000). Les relations publiques dans une société en mouvance, Sainte-Foy, Presses de l'Université du Québec.

MATRAT, L. (1971). Relations publiques et management, Bruselas, CERP.

MATRAT, L. (1975). "Doctrine européenne des relations publiques, condition du dialogue et de la participation", Estudios de Comunicación Social y Relaciones Públicas, 1, 29-33.

MATRAT, L. (1987). "Quel avenir pour les relations publiques? Quel avenir pour la profession?", Selection CERP/87, 7-12.

NEWSOM, D., TURK, J.V. y KRUCKEBERG, D. (2000). This is PR: The realities of public relations, Belmont, Wadsworth, 7ª edición.

REVILLA, F. (1970). Hacerlo bien y hacerlo saber, Barcelona, Oikos-Tau.

SOLANO, L. (1995). Fundamentos de las relaciones públicas, Madrid, Síntesis.

UGEUX, W. (1973). Les relations publiques, Verviers, Gerard \& Co (trad. cast.: Las relaciones públicas: Una nueva función social, Barcelona, Seix y Barral, 1976).

XIFRA, J. (2005). Planificación estratégica de las relaciones públicas. Barcelona: Paidós.

XIFRA, J. (2006). Teoría y técnicas de las relaciones públicas II. Barcelona: Fundación UOC. 